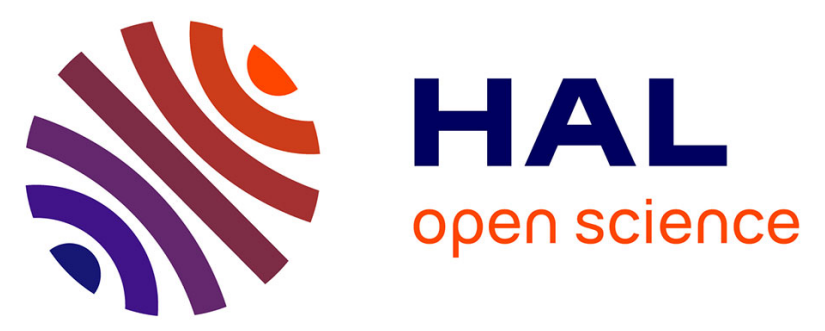

\title{
Knowledge, attitudes, and practices of health sciences students regarding epilepsy at the end of their curriculum in Benin
}

\author{
Charlemagne Vodougnon, Daniel Gérard, Pierre-Emile Bruand, Emilie
} Auditeau, Farid Boumédiène, Inès Yoro Zohoun, Dieudonné Gnonlonfoun, Dismand Houinato, Pierre-Marie Preux

\section{To cite this version:}

Charlemagne Vodougnon, Daniel Gérard, Pierre-Emile Bruand, Emilie Auditeau, Farid Boumédiène, et al.. Knowledge, attitudes, and practices of health sciences students regarding epilepsy at the end of their curriculum in Benin. Epilepsy \& Behavior Case Reports, 2019, 92, pp.165-170. hal-01984607

\section{HAL Id: hal-01984607 \\ https://hal-unilim.archives-ouvertes.fr/hal-01984607}

Submitted on 21 Oct 2021

HAL is a multi-disciplinary open access archive for the deposit and dissemination of scientific research documents, whether they are published or not. The documents may come from teaching and research institutions in France or abroad, or from public or private research centers.
L'archive ouverte pluridisciplinaire HAL, est destinée au dépôt et à la diffusion de documents scientifiques de niveau recherche, publiés ou non, émanant des établissements d'enseignement et de recherche français ou étrangers, des laboratoires publics ou privés.

\section{(ㅇ)(1) $\$$}

Distributed under a Creative Commons Attribution - NonCommerciall 4.0 International 


\title{
Knowledge, Attitudes and Practices of health sciences students regarding epilepsy at the end of their curriculum in Benin
}

Charlemagne Vodougnon*a,b, Daniel Gérard ${ }^{c}$, Pierre-Emile Bruand ${ }^{c}$, Emilie Auditeau ${ }^{a}$, Farid Boumediene ${ }^{a}$, Inès Yoro Zohoun ${ }^{a, b}$, Dieudonné Gnonlonfoun ${ }^{b}$, Dismand Houinato ${ }^{a, b}$, Pierre-Marie Preux ${ }^{b}$.

\author{
a INSERM, Univ. Limoges, CHU Limoges, UMR 1094, Tropical Neuroepidemiology, Institute of \\ Neuroepidemiology and Tropical Neurology, GEIST, 87000 Limoges, France \\ ${ }^{b}$ LEMACEN, University of Abomey-Calavi, Cotonou, Benin \\ ${ }^{c}$ Global Health Programs, Sanofi, France \\ *Corresponding author \\ Address e-mail: charvodji@gmail.com
}

\begin{abstract}
Objective: The main objective of this study was to evaluate the knowledge, attitudes and practices (KAP) of health sciences students regarding epilepsy at the end of curriculum in Benin.
\end{abstract}

Methods: We conducted a cross-sectional survey among medical, pharmacy, nursing and midwife students in their last-year of health sciences training in University of Abomey-Calavi in Benin. Students completed a self-administered questionnaire, containing items addressing demographics, epilepsy treatment, diagnosis, clinical practice, and social tolerance regarding person with epilepsy.

Results: The response rate to our survey was $87.7 \%(n=164)$. The sample consisted of 64 medical students, 22 pharmacy students, 43 nursing students and 35 midwife students. They were divided into 95 female subjects and 69 male; sex ratio was 0.7 . The mean age of participants was $23.6 \pm 1.8$ years. The mean scores for epilepsy knowledge, practices and attitudes were respectively $7.6 \pm 1.7$ out of a maximum score of $11,3.9 \pm 1.8$ out of 8 and 9.6 \pm 0.8 out of 10. The KAP overall score was $21.1 \pm 3.4$ out of a maximum score of 29.0. The variables associated with the overall KAP score were training school, gender, having heard 
about epilepsy before health sciences studies $(p=0.017)$ and having a relative with epilepsy $(p=0.001)$. Male students and medical school students had significantly better overall KAP score than female students or the other training schools respectively $(p<0.001)$.

Significance: These findings support the need to improve health sciences students' knowledge of epilepsy in particular during their training.

Key words: Epilepsy, health sciences students, last year of training, KAP, Benin.

\section{KEY POINTS}

- Epilepsy is a major public health problem in Benin.

- There is a research gap on the assessment in health care workers knowledge about epilepsy in Benin.

- Health sciences students' knowledge about epilepsy at the end of their curriculum in Benin is relatively low.

\section{INTRODUCTION}

Epilepsy is one of the most common chronic disease of the central nervous system[1]. It affects more than 70 million people worldwide; most live in low and middle income countries and do not receive appropriate treatment[2]. In Africa as well as other parts of the world, epilepsy continues to be perceived by many as a supernatural, contagious, and shameful disease [3-6]. This limits the search for appropriate care, and contributes to a greater treatment gap in developing countries as patients are often hidden and stigmatized $[3,4,7,8]$.

Healthcare workers including physicians, nurses, clinical officers, pharmacist... are the main stakeholders in the management of person with epilepsy (PWE) particularly in developing countries $[9,10]$. It is important that they have good medical knowledge about the disease as well as be aware of its socio-cultural representations in different communities [11]. However, studies on perceptions of epilepsy among healthcare workers have shown a lack of knowledge about the disease. A survey conducted among Zambian health care workers (nurses and clinical officers) showed that $54.8 \%$ of them think that epilepsy is due to mental illness and $5.6 \%$ to a contagious disease [9]. In Laos, $60.4 \%$ of a total of 48 physicians 
in a survey believed that epilepsy could be transmitted through saliva[12]. Healthcare workers are not often socially tolerant of people with epilepsy. In the Zambian survey, $25.2 \%$ of them would oppose the marriage of their son with a PWE; 3.6\% believes a child with epilepsy should never attend school [9]. In Saudi Arabia, 67\% of the 822 medical and paramedical personnel surveyed said they would oppose the marriage of their child with a PWE [13]. Levels of education and occupation were correlated with the level of knowledge about epilepsy and with a better social tolerance of PWE $[9,13]$. Healthcare workers who had completed practical internships, in addition to theoretical curriculum on epilepsy during their training, had a better understanding of the disease [9].

Healthcare workers recognized that their knowledge about epilepsy was limited $[14,15]$. Barriers that limit appropriate management of PWE, identified by healthcare workers, are the difficulties in acute management and recognition of partial epilepsy, in managing pregnant woman with epilepsy and in the managing the stigma $[12,16,17]$. Studies conducted among healthcare workers about epilepsy do not always take into account the time elapsed since the end of training in vocational schools $[13,17,18]$. Thus, when the level of knowledge seems insufficient, it may be due to a lack of initial knowledge (failure in acquisition during their curriculum) or to a loss over time of knowledge initially acquired. In Cameroon, $6 \%$ of medical students considered epilepsy to be contagious, $10 \%$ of preclinical students and $3.3 \%$ of clinical students could not tell a cause of epilepsy [19]. More than $80 \%$ of first-year medical students at Mulago Hospital in Kampala said that they would not allow their children to marry PWE. Most respondents believed that epilepsy was a mental illness, and many believed that PWE cannot have normal intelligence [20]. These misperceptions must be identified and corrected among medical students during the training.

Epilepsy is a major public health problem in Benin as in more sub-Saharan Africa countries, with nationwide representative prevalence of 08.05 [21]. Like other African countries, Benin faces a shortage of neurologist; leaving responsibility for the care of PWE to general practitioners, nurses and midwives; pharmacists are also involved. Benin has three universities in which are trained health care workers. University of Abomey-Calavi is the oldest and has a medical school, a faculty of pharmacy, dentistry, and a nursing and midwifery school. The University of Parakou in the north has a medical school and a training school for nurses. Finally the University of Porto Novo, the latest has a medical school. It 
takes 7 years to graduate as a Medical Doctor and 6 years as a Pharmacist. Nurses and midwives would get their professional license after 3 years of study. During their curriculum, medical students benefit from 28 hours of neurology classes divided into 12 hours of semiology (2nd year), 10 hours of pathology (4th year) and 6 hours of therapy in 5th year. The hourly load devoted to epilepsy is 6 hours ( 2 hours per year). Apart from the therapeutic courses, pharmacists have the same neurology content as physicians, but are taught in 2nd and 3rd year. Nurses and midwives receive, in the third year, the same 8 hours neurology program, including 2 hours devoted to epilepsy. Each of these student categories complete hospital internships during their curriculum; completing this internship in a neurology department is a choice; some students can finish their training without setting foot in a neurology department.

Prior knowledge, attitudes, beliefs, and practice surveys conducted in Benin have been directed at the general public, students, or teachers $[3,5,22-26]$. There is no study to our knowledge that is focused on the knowledge, attitudes and practices of healthcare professionals, much less healthy school students on epilepsy in Benin.

The main objective of this study was to determine the level of knowledge of health students about epilepsy at the end of their curriculum in Benin.

\section{METHODS}

We conducted between May 6th and 16th 2016 a cross-sectional survey among health sciences students in their final year of studies in Benin.

Benin is a sub-Saharan Africa country bounded by Burkina-Faso and Niger in the North, Togo in the West and Nigeria in the East. The country is extends from the Niger River in the North to Atlantic Ocean in the South with an area of $112.622 \mathrm{~km}^{2}$. The estimation population in Benin was 11.186.785 inhabitants in 2017 [27].

\subsection{Study setting}

The study was conducted at the Faculté des Sciences de la Santé (FSS) and at the Institut National Médico-sanitaire (INMES), two entities of Abomey-Calavi University in Benin. University of Abomey-calavi was chosen because it is the only one that trains both 
students in medicine, pharmacy, nursing and midwifery. We had ensured they had finished the neurology program, both theoretical and internships.

After having obtained the approvals of the Dean of Faculté des Sciences de la Santé Dean and the Director of Institut National Médico-sanitaire, all students were invited (medical and pharmacy students on the one hand and nurse and midwife students on the other) to participate at a conference on research methodology and epidemiological studies. The subject of the study had not been communicated to them in advance to avoid information bias. During the conference, the KAP study was presented to students and their free and informed consent was requested. All students present agreed to participate in the study.

\subsection{Instrument}

After reviewing several knowledge, attitudes, beliefs and practices instruments used by other groups studying epilepsy $[9,12,13,22,28-30]$, we developed a 41-item questionnaire. The most common questions about KAP were kept and other items related to symptoms, diagnosis and management of epilepsy were added (appendix). The questionnaire was divided into two sections. The first section included sociodemographic information and general questions about epilepsy (Q1-Q14). The second part was related to KAP (Q15-Q41) and assessed the basic knowledge that any health provider should have about epilepsy. This part could be subdivided into three areas (knowledge, attitudes and practices). "Knowledge" questions were related epilepsy diagnosis; the "Practices" chapter was related with epilepsy clinical management and "Attitudes" questions were related to social tolerance regarding person with epilepsy.

There were three different types of questions based on the responses that were possible. The first group was closed questions leaving only the choices of yes or no, true or false and I don't know. The second type was multiple choice questions (several qualitative answers were proposed) and recognition responses. The last one collected opinions of the professionals on the different attitudes towards the stigma on epilepsy. The choice of answers was: Strongly disagree, Disagree, Agree, Totally agree.

To facilitate comparison between groups, we developed three scores; "Knowledge score" (Q12-Q22), "Practice score" (Q23-Q30) and "Attitude score" (Q31-Q40). The sub- 
questions were not taken into account in calculating the different scores since they provided additional information regarding the questions that preceded them. The various response options for each question were reduced to a dichotomous alternative, "Yes"/"No" for the rating. The answers "False" and "I don't know" was deemed equivalent to "No", "True" to "Yes". A correct answer to a multiple choice question became a "Yes", an incorrect answer, or the choice of both correct and incorrect answers to the same question became a "No". For questions on opinions, "Agree" or "Strongly agree" was deemed equivalent to "Yes"; and "disagree" or "totally disagree" to "No". Correct answers were rated 1 and incorrect answers 0 . The score for each domain was the sum of all the individual scores for each question in that specific domain. Thus, the scores ranged from 0 to 11,0 to 8 and 0 to 10 respectively for the knowledge, practice and attitude of healthcare professionals regarding epilepsy. The overall KAP score, which is the sum of the three domain scores, ranged from 0 to 29. To help with the interpretation of the results, the overall KAP score has been transformed into several categories. They consisted in 7 classes [31] : Excellent (26-29), Very good (23-25), Good (20-22), Fairly good (17-19), Fair (15-16), Low (12-14), Nil (0-11). The Excellent range was considered as the reference level of knowledge.

Question 41 was about students' own judgment about their epilepsy knowledge. The different options in terms of responses were Good, Acceptable and Limited.

The questionnaire was pre-tested on a pilot group of fourth-year medicine students for accuracy and comprehension. This allowed the wording of some of the questions to be adjusted to be better understood by students. The minimum time to complete the questionnaire was 9 minutes and the maximum 25 minutes.

The questionnaire was administered in the form of a self-administered questionnaire. Questionnaires were completed anonymously under the supervision of investigators so that students will work together to answer.

\subsection{Statistical analysis}

Data analysis was performed using Epi Info 3.5.4. Descriptive variables were expressed as mean, standard deviation, or percentage. The scores were analyzed as continuous variables. A univariate analysis using Kruskal-Wallis test was used to compare the different scores. A p-value of less than $5 \%$ was considered statistically significant. 


\section{RESULTS}

\subsection{Demographic characteristics and experience with epilepsy}

There was a total of 187 health students at the end of their curriculum at the University of Abomey-Calavi, including 76 medical students, 26 pharmacy students, 46 nursing and 39 midwifery students. One hundred and sixty-four (164) subjects participated in the study, representing an overall participation rate of $87.7 \%$. They consisted of 64 medical students, 22 pharmacy students, 43 nurse students and 35 midwife students. They were divided into 95 female subjects and 69 male; the sex ratio was 0.7 . The overall average age was $23.6 \pm 1.8$ years. The most represented age range was $25-29$ years old (69.5\%) (Figure 1). Male subject's average age was $24.03 \pm 1.9$ and $23.24 \pm 1.6$ for female.

Out of the total number of survey participants, $67.7 \%$ had witnessed at least one epileptic seizure, while $14 \%$ had a close family member/friend with epilepsy. Table 1 shows demographics characteristics of the survey participants.

\subsection{Health sciences students knowledge about epilepsy}

The average knowledge score was 7.6 and ranged from 3 to 11 (standard deviation 1.7, median 8). The different responses to questions on knowledge are reported in Table 2. Epilepsy was recognized as a neurological disease by almost all subjects (99.4\%). On the other hand, its definition as the occurrence of at least two epileptic seizures, unrelated to a particular situation, was known only by half of the subjects. About $30 \%$ believed that epilepsy was always hereditary and $6.7 \%$ thought (midwives mainly) it was contagious. All subjects knew that epilepsy was not due to divine punishment, nor to a curse or to witchcraft.

\subsection{Attitudes of health sciences students regarding person with epilepsy}

Health sciences students as a whole were quite supportive of people with epilepsy. All of them stated that children with epilepsy should be educated in the same way as other children and in the same institutions. However, $3.1 \%$ of medical students, $13.0 \%$ of pharmacy students, $44.2 \%$ of nursing students and $40.0 \%$ of midwifery students were unfavorable to physical and sports activities for PWE. About $4.7 \%$ of nursing students and $8.6 \%$ of midwifery students suggested that parents should forbid their child from playing with PWE. All survey participants were of the opinion that PWE could have a child and that 
parents should not oppose the marriage of their child with a PWE except for $11.4 \%$ of midwifery students who stated that parents should discourage their child from marrying a PWE. In the workplace, $4.7 \%$ of nursing students, $3.1 \%$ of medical students and $2.9 \%$ of midwifery were not in favor of PWE sharing the same workspace as healthy subjects. A small number of nursing and midwifery students were of the opinion that public places should be prohibited to PWE (2.3 and 5.7\%, respectively).

The average score on attitudes was 9.6 with a range of 9 to 10 . All categories had a score greater than 9.

\subsection{Practices of health sciences students regarding person with epilepsy}

In response to what should be done when witnessing someone having a generalized tonic-clonic seizure, $4.7 \%$ of medical students, $4.7 \%$ of nursing students and $25.7 \%$ of midwifery students recommended to prevent the convulsion by overpowering the individual through force. Introduction of an object into the person's mouth to prevent tongue-biting was proposed by one-third of nursing students (32.6\%), one-fifth of medical students $(20.3 \%)$, half of pharmacy students (59.1) and more than one in three midwifery students (65.7). Health sciences students' practices for epilepsy are presented in Table 3.

The mean score on health sciences students' Practices for Epilepsy was $3.9 \pm 1.8$. The median was 4 and the range was 0 to 8 .

\subsection{0verall KAP score of health sciences students on epilepsy and associated factors}

The mean KAP score of health sciences students surveyed was $21.1 \pm 3.4$ out of 29 . The median was 21 , the lowest score was 10 and the highest 28 . None of the subjects surveyed had a total score of 29 out of 29 . The mean overall KAP score for each category was $23.3 \pm 2.4$ for medical school students, $21.2 \pm 2.6$ for pharmacy students, $20.9 \pm 2.4$ for nursing school students and $17.2 \pm 2.9$ for midwifery students. Figure 2 shows the ranking according to the qualitative scale of the average scores of each health sciences student's category.

Overall, $11.6 \%$ of subjects rated their overall level of knowledge on epilepsy as good, $46.3 \%$ as acceptable, and $42.1 \%$ as limited. 
The variables associated with the overall KAP score were training school, gender, having heard about epilepsy before health sciences studies $(p=0.017)$ and having a relative with epilepsy $(p=0.001)$ (table 4). Male students and medical school students had significantly better overall KAP score than female students or the other training schools respectively $(p<0.001)$.

A significant positive correlation was found between the level of knowledge and the level of practices $(r=0.29, P<0.001)$, and with the level of attitudes $(r=0.09, p<0.001)$.

\section{DISCUSSION}

This study was conducted to determine the level of epilepsy knowledge of health sciences students at the end of their studies in Benin. The participation rate was $87.7 \%$. The mean of overall KAP score was $21.1 \pm 3.4$ out of 29 . It was considered low because a score ranging from 26 to 29 was established as the reference level of knowledge. Male students, those with a close family member or friend with epilepsy, and medical students had a significantly better level of knowledge about epilepsy than others.

The study was conducted using a questionnaire designed after reviewing in literature several knowledge, attitudes, beliefs and practices instruments used by other groups studying epilepsy. A composite score has been created to allow comparison between groups. Pre-testing ensured that the different questions were understood by the students. The filling of the questionnaire in the presence of the investigator ensured the individuality of the answers. Moreover, the students had only been informed about the study during the working session, this eliminates potentials information bias. The participation rate of about $90 \%$ ensures a good representation of our sample.

Despite these positives, our study has some shortcomings. Indeed, while this is obvious, it will be difficult for us to make a pronouncement about the actual contribution of medical studies to students' knowledge because of the study design. A comparative study with other students at the end of non-medical course, or a quasi-experimental study type before / after would have been more appropriate. Also, for more reliability of our collection tool, it would have been interesting to precede our study of a questionnaire validation survey. 
The subjects had witnessed an epileptic seizure in $67.7 \%$ of the cases. This value is significantly lower than the $80.7 \%$ reported by Njamnshi et al. in medical students in Cameroon [19]. This proportion exceeds ours because recruitment was done on a larger population (students of the fourth in the seventh year of medicine). Moreover, the low rate obtained by students in pharmacy and midwife who do not attend many cases of seizures because of their work has influenced our proportion (Table 1). Our value is also significantly lower than the $98.2 \%$ of controls in the survey of healthcare workers in Zambia [9]. The difference could be explained by the fact that Zambians were already practicing healthcare providers and, as a result, had more experience with epilepsy.

The notion that epilepsy is a neurological disease was confirmed by almost all of the subjects surveyed. Health sciences' training has certainly helped to remove the socio-cultural representations which attribute a supernatural origin to the disease, or which links it to uncleanliness [3]. The majority (89.9\%) of Cameroon health sciences students recognized that epilepsy is caused by brain disorder. However some health sciences students like firstyear medical students at Mulago Hospital in Kampala thought that epilepsy is a mental retardation (10\%) or a spirit possession (5\%) [20]. This findings show that students at the beginning of medical training have less knowledge about epilepsy than their seniors $[32,33]$. In a study conducted in India among students who were not studying health sciences, 59.3\% claimed that epilepsy was due to mental retardation [34]. These results also confirm the contribution of health sciences training to the understanding of epilepsy. However, in some cases, there can also be misconceptions about epilepsy among health sciences students. Our study showed that $6.7 \%$ of students mainly midwives believed that epilepsy is contagious. In Cameroon, only $0.7 \%$ of medical students said it was contagious [19]. In Laos, $33.3 \%$ of physicians thought it was a communicable disease [12]. This means that even in the health care workers already operating, gaps about epilepsy knowledge exists. Belief in the contagiousness of epilepsy through direct contact with the PWE, or with their body fluids (saliva, urine, tears in this study) can exacerbate attitudes of fear and rejection. Epilepsy was seen as a hereditary disease by $28.7 \%$ of the subjects surveyed. This rate is lower than the 40.3\% found in a study of medical students at the University of Manipal in India [29]. This difference is understandable since the population of the Indian study consisted of students in their first year at medical school. 
The subjects in our study had a fairly good social tolerance towards PWE. None of the medical students stated that they would object to their child marrying a PWE or that they would prevent children with epilepsy from going to the same schools as other children, contrary to the opinion of first-year medical students at Mulago Hospital in Kampala who would not allow their child to marry someone with epilepsy(20). Physicians in Laos would oppose to the marriage of their children with a PWE (70.8\%) and $24.3 \%$ wouldn't allow their children going to the same school as children with epilepsy [12].

As in the case with the general population, generalized tonic-clonic seizure was easily recognized by healthcare professionals at the end of their studies. In our study, only $37.2 \%$ of subjects (all categories combined) were able to identify partial epilepsies. This result is higher than the $20 \%$ obtained by already practicing medical staff in the Zambian study [9]. The practice of health sciences students when faced with an epileptic seizure is not without consequence since some actions to avoid were found in the various responses obtained in this study. For example, preventing seizures by controlling the patient by force or giving medication by mouth are attitudes which should be avoided; fractures, dislocations or choking could occur.

Epilepsy can be treated. Our study showed that $25 \%$ of nursing students, $25 \%$ of pharmacy students, and $20 \%$ of midwifery students thought the opposite. The treatment of epilepsy is not always lifelong. Indeed, stopping antiepileptic drugs (AED) could be considered for a treated PWE after two to five years without seizure. Under these conditions, the AED dosage would be gradually reduced until complete discontinuation of the drug. Some of the nurses and midwives in our study believed that PWE had to follow dietary restrictions. This notion is often found in popular beliefs, especially in sub-Saharan Africa, where the consumption of these foods would increase the foam ("drool") that flows from the mouth of the subject during a seizure [35]. Bamileke traditional healers in Cameroon and Akan traditional healers in Ivory Coast banned all meat consumption during the treatment of epilepsy $[35,36]$. They did not necessarily make the link between meat consumption and the occurrence of seizures, but they thought that undercooked meat could be the cause of some diseases, without necessarily thinking about epilepsy. 
Overall, our study showed that medical students have a better level of knowledge than the rest of the health sciences students. This result confirms what is found in the literature [28]. Such a result is hardly surprising since, of the four professional categories, medical students benefit from more hours of epilepsy training and do more internship in different hospital departments during their university curriculum. It could also be that the content of the training for medical students is different from that of pharmacy students, even if it is on the same topic. Since medical students will be prescribers, teachers will tend to emphasize what would promote a good understanding of the disease, its diagnosis and its management. Although this difference is not statistically significant in our study, health sciences students who have done internships in a hospital department, in addition to lectures on epilepsy, have a better overall knowledge of the disease. This result reflects the importance of traineeship in hospital settings as part of the training of health sciences students. None of the subjects surveyed were able to correctly answer all of the questions included in the KAP questionnaire and very few had an excellent level of epilepsy knowledge. These results reflect a relatively low level of knowledge for health sciences students about epilepsy at the end of their curriculum in Benin. The KAP questionnaire, however, included basic questions about epilepsy for which all students should get all the correct answers. Most of these students were aware of their level of knowledge about the disease. Others, who described their knowledge as good or acceptable, when in fact it was not, represent a potential danger to patients.

\section{CONCLUSION}

It appears from this study that the overall level of knowledge about epilepsy among health sciences students at the end of their curriculum in Benin, whatever the category is relatively low. These future healthcare workers will certainly be confronted, on the ground, with the difficulties of taking care of PWE. Actions to improve knowledge and attitudes of health sciences students could improve future management of patients with epilepsy.

\section{ACKNOWLEDGEMENTS}

- Healthcare professionals in the last years of medical and paramedical studies at University of Abomey-Calavi 
- Sanofi Global Health Programs staff

- Physicians in neurology specialization studies at University of Abomey-Calavi.

\section{CONFLICT OF INTEREST STATEMENT}

- Charlemagne Vodougnon was an intern at Sanofi for 6 months during which he received a grant

- Pierre Emile Bruand is a Sanofi employee and owns Sanofi stocks

- Daniel Gerard is a former employee of Sanofi

- Other authors do not have any conflict of interest to disclose

\section{REFERENCES}

[1]. Global Campaign against Epilepsy, International Bureau of Epilepsy, International League against Epilepsy. Atlas: epilepsy care in the world. Geneva: Programme for Neurological Diseases and Neuroscience, Department of Mental Health and Substance Abuse, World Health Organization; 2005. 91 p.

[2]. Ngugi AK, Bottomley C, Kleinschmidt I, Sander JW, Newton CR. Estimation of the burden of active and life-time epilepsy: a meta-analytic approach. Epilepsia. mai 2010;51(5):883 ?90.

[3]. Rafael F, Houinato D, Nubukpo P, Dubreuil C-M, Tran DS, Odermatt P, et al. Sociocultural and psychological features of perceived stigma reported by people with epilepsy in Benin. Epilepsia. juin 2010;51(6):1061?8.

[4]. Lim Y-J, Chan S-Y, Ko Y. Stigma and health-related quality of life in Asian adults with epilepsy. Epilepsy Res. déc 2009;87(20?3):107?19.

[5]. Rafael F, Dubreuil C, Prado JA, Burbaud F, Clement J, Preux P, et al. Social and cultural representation of Epilepsy in elderly aged 65 and more, during a community survey in two French Departments (Hautevienne and Creuse). Ann Neurosci. avr 2010;17(2):60?2.

[6]. Adjei P, Akpalu A, Laryea R, Nkromah K, Sottie C, Ohene S, et al. Beliefs on epilepsy in Northern Ghana. Epilepsy Behav EB. nov 2013;29(2):316国21.

[7]. Meinardi H, Scott RA, Reis R, Sander JW, ILAE Commission on the Developing World. The treatment gap in epilepsy: the current situation and ways forward. Epilepsia. janv 2001;42(1):136目49. 
[8]. Atadzhanov M, Haworth A, Chomba EN, Mbewe EK, Birbeck GL. Epilepsy-Associated Stigma in Zambia: What factors predict greater felt stigma in a highly stigmatized population? Epilepsy Behav EB. nov 2010;19(3):414?8.

[9]. Chomba EN, Haworth A, Atadzhanov M, Mbewe E, Birbeck GL. Zambian health care workers' knowledge, attitudes, beliefs, and practices regarding epilepsy. Epilepsy Behav EB. févr 2007;10(1):111国9.

[10]. Elliott J, Shneker B. Patient, caregiver, and health care practitioner knowledge of, beliefs about, and attitudes toward epilepsy. Epilepsy Behav EB. mai 2008;12(4):547国56.

[11]. Sands H, Zalkind SS. Effects of an Educational Campaign to Change Employer Attitudes toward Hiring Epileptics. Epilepsia. 1 janv 1972;13(1):87096.

[12]. Harimanana A, Chivorakul P, Souvong V, Preux P-M, Barennes H. Is insufficient knowledge of epilepsy the reason for low levels of healthcare in the Lao PDR? BMC Health Serv Res. 4 févr 2013;13:41.

[13]. Alaqeel A, Alebdi F, Sabbagh AJ. Epilepsy: What do health-care professionals in Riyadh know? Epilepsy Behav EB. oct 2013;29(1):234?7.

[14]. Hayes SM, Melin JD, Dupuis M, Murray S, Labiner DM. Assessing the true learning needs of health care professionals in epilepsy care. Epilepsy Behav EB. nov 2007;11(3):434目41.

[15]. Patient, caregiver, and health care practitioner knowledge of, beliefs about, and attitudes toward epilepsy. - PubMed - NCBI [Internet]. [cité 21 nov 2018]. Disponible sur:

https://www.ncbi.nlm.nih.gov/pubmed/?term=Patient\%2C+caregiver\%2C+and+health+ care+practitioner+knowledge+of\% $2 \mathrm{C}+$ beliefs+about $\% 2 \mathrm{C}+$ and+attitudes+toward+epilep sy

[16]. Thompson R, Linehan C, Glynn M, Kerr MP. A qualitative study of carers' and professionals' views on the management of people with intellectual disability and epilepsy: a neglected population. Epilepsy Behav EB. sept 2013;28(3):379?85.

[17]. Keikelame MJ, Hills RM, Naidu C, de Sá A, Zweigenthal V. General practitioners' perceptions on management of epilepsy in primary care settings in Cape Town, South

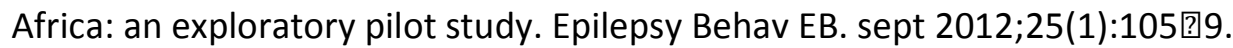

[18]. Blank L, Baxter S, Baird W, Reuber M. Understanding referral patterns to an epilepsy clinic: professional perceptions of factors influencing the referral of older adults. Seizure. nov 2013;22(9):698?702.

[19]. Njamnshi AK, Angwafor SA, Baumann F, Angwafo FF, Jallon P, Muna WFT. Knowledge, attitudes, and practice of Cameroonian medical students and graduating physicians with respect to epilepsy. Epilepsia. mai 2009;50(5):1296?9. 
[20]. Bigelow J, Berrett S, Kimuli I, Katabira E. Perceptions of epilepsy among first-year medical students at Mulago Hospital in Kampala, Uganda. Epilepsy Behav EB. oct 2015;51:28?32.

[21]. Yemadje L-P, Houinato D, Boumédiène F, Ngoungou EB, Preux P-M, Druet-Cabanac M. Prevalence of epilepsy in the 15 years and older in Benin: a door-to-door nationwide survey. Epilepsy Res. mai 2012;99(3):318?26.

[22]. Hounsossou CH, Queneuille JP, Ibinga E, Preux PM, Dalmay F, Druet-Cabanac M, et al. Knowledge, attitudes, and behavior among key people involved in the employment of people with epilepsy in southern Benin. Epilepsy Behav EB. janv 2015;42:153 ? 8 .

[23]. Adoukonou T, Tognon-Tchegnonsi F, Gnonlonfoun D, Djidonou A, Sego-Sounon D, Gandaho $\mathrm{P}$, et al. [Socio-cultural aspects of epilepsy in a rural community in northern Benin in 2011]. Bull Soc Pathol Exot 1990. mars 2015;108(2):133?8.

[24]. Nubukpo P, Preux PM, Clement JP, Houinato D, Tuillas M, Aubreton C, et al. [Comparison of sociocultural attitudes towards epilepsy in Limousin (France), in Togo and in Benin (Africa)]. Med Trop Rev Corps Sante Colon. 2003;63(2):143团50.

[25]. Nubukpo P, Clément JP, Houinato D, Radji A, Grunitzky EK, Avodé G, et al. Psychosocial issues in people with epilepsy in Togo and Benin (West Africa) II: quality of life measured using the QOLIE-31 scale. Epilepsy Behav EB. oct 2004;5(5):728 ?34.

[26]. Nubukpo P, Preux PM, Houinato D, Radji A, Grunitzky EK, Avodé G, et al. Psychosocial issues in people with epilepsy in Togo and Benin (West Africa) I. Anxiety and depression measured using Goldberg's scale. Epilepsy Behav EB. oct 2004;5(5):722 7.

[27]. INSAE - Institut National de la Statistique et de l'Analyse Économique [Internet]. [cité 13 nov 2018]. Disponible sur: https://www.insae-bj.org/

[28]. Vancini RL, Benedito-Silva AA, Sousa BS, Gomes da Silva S, Souza-Vancini MI, VanciniCampanharo $\mathrm{CR}$, et al. Knowledge about epilepsy among health professionals: a crosssectional survey in Sao Paulo, Brazil. BMJ Open. 2012;2(2):e000919.

[29]. Panda SB, Prabhu K, Rao S, Rao A, Rao G, Datta A, et al. Evaluation of knowledge of and attitudes toward epilepsy among the health science students of Manipal University. Epilepsy Behav EB. mars 2011;20(3):447?9.

[30]. Roth Y, Neufeld MY, Blatt I, Guy-Alfandary S, Rasaby S, Ekstein D, et al. An evaluation of pharmacist knowledge on treatment with antiepileptic drugs. Seizure. janv

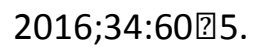

[31]. Dorota T, Witkowska M, Michalak M. Attitudes of employees of service and trading companies towards people with epilepsy and their professional activity in Poland. Seizure - Eur J Epilepsy. 1 mars 2014;23(3):178?83. 
[32]. Fonseca LC, Tedrus GMAS, Costa ACF, Luciano PQ, Costa KC. [Knowledge and attitude toward epilepsy among health area students]. Arq Neuropsiquiatr. déc 2004;62(4):1068?73.

[33]. Tedrus GMAS, Fonseca LC, Vieira AL da C. Knowledge and attitudes toward epilepsy amongst students in the health area: intervention aimed at enlightenment. Arq

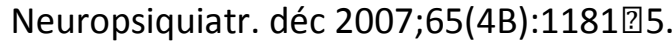

[34]. Pandian JD, Santosh D, Kumar TS, Sarma PS, Radhakrishnan K. High school students' knowledge, attitude, and practice with respect to epilepsy in Kerala, southern India. Epilepsy Behav EB. nov 2006;9(3):492目7.

[35]. Nkwi PN, Ndonko FT. The epileptic among the Bamileke of Maham in the Nde Division, West Province of Cameroon. Cult Med Psychiatry. déc 1989;13(4):4370 48.

[36]. François AA, Elisée BK, Christian TA, Armel KH, Any G, Tchwa AM, et al. [Traditional health practitioners and epilepsies in Ivory Coast]. Rev Neurol (Paris). sept 2014;170(809):508?11. 


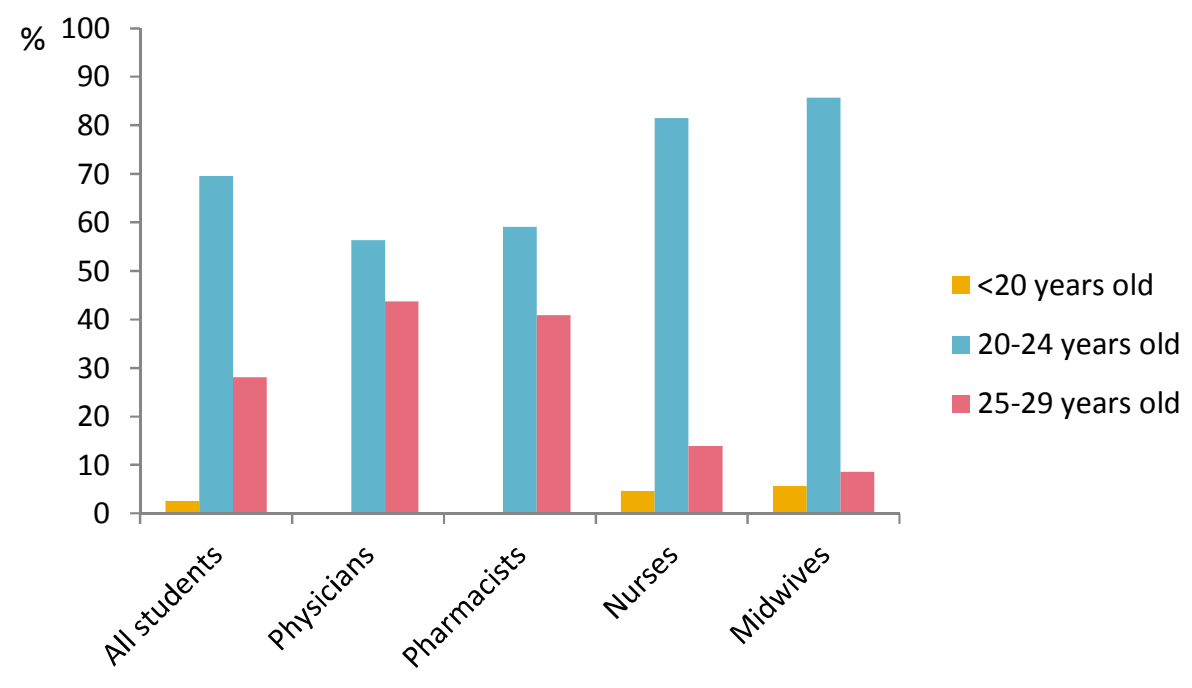

Figure 1: Distribution of health sciences students by age range 


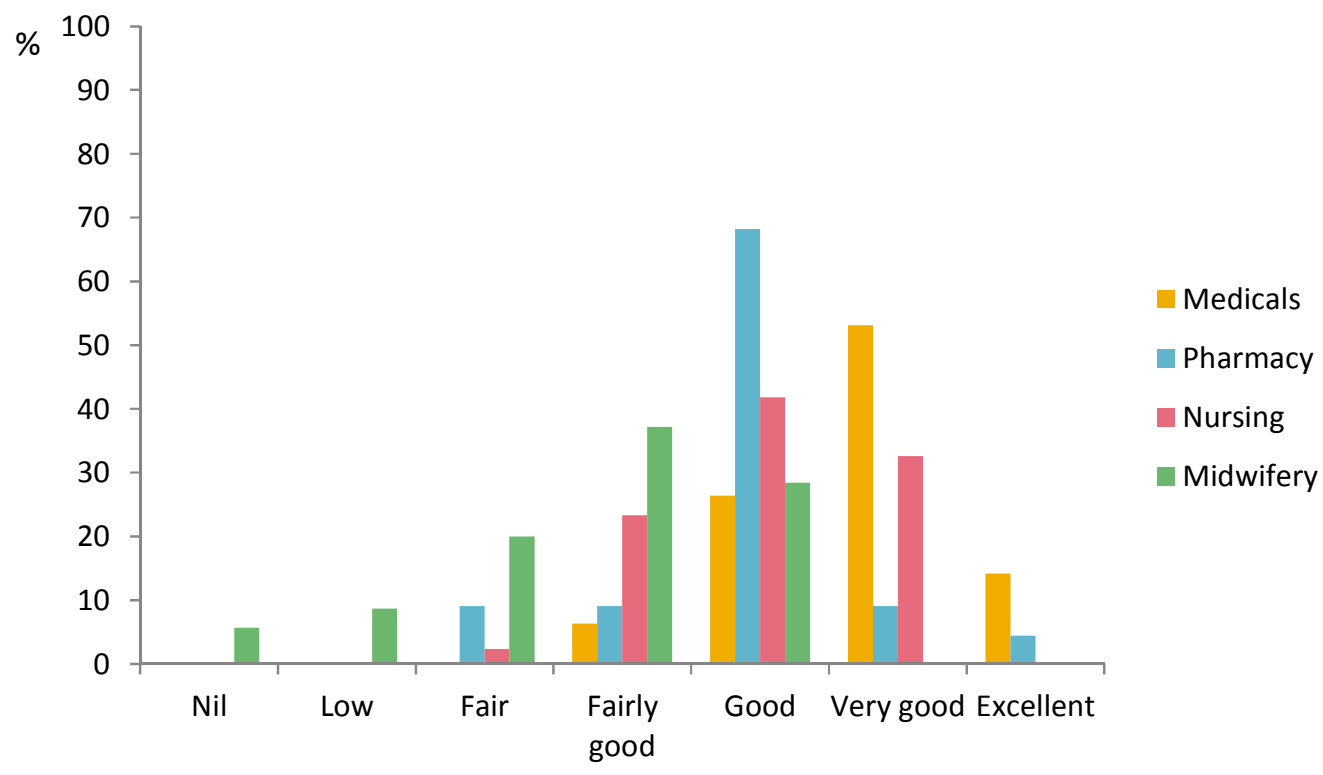

Figure 2: Qualitative classification of KAP score averages 
Table 1: Demographic characteristics and experience with epilepsy of health sciences students

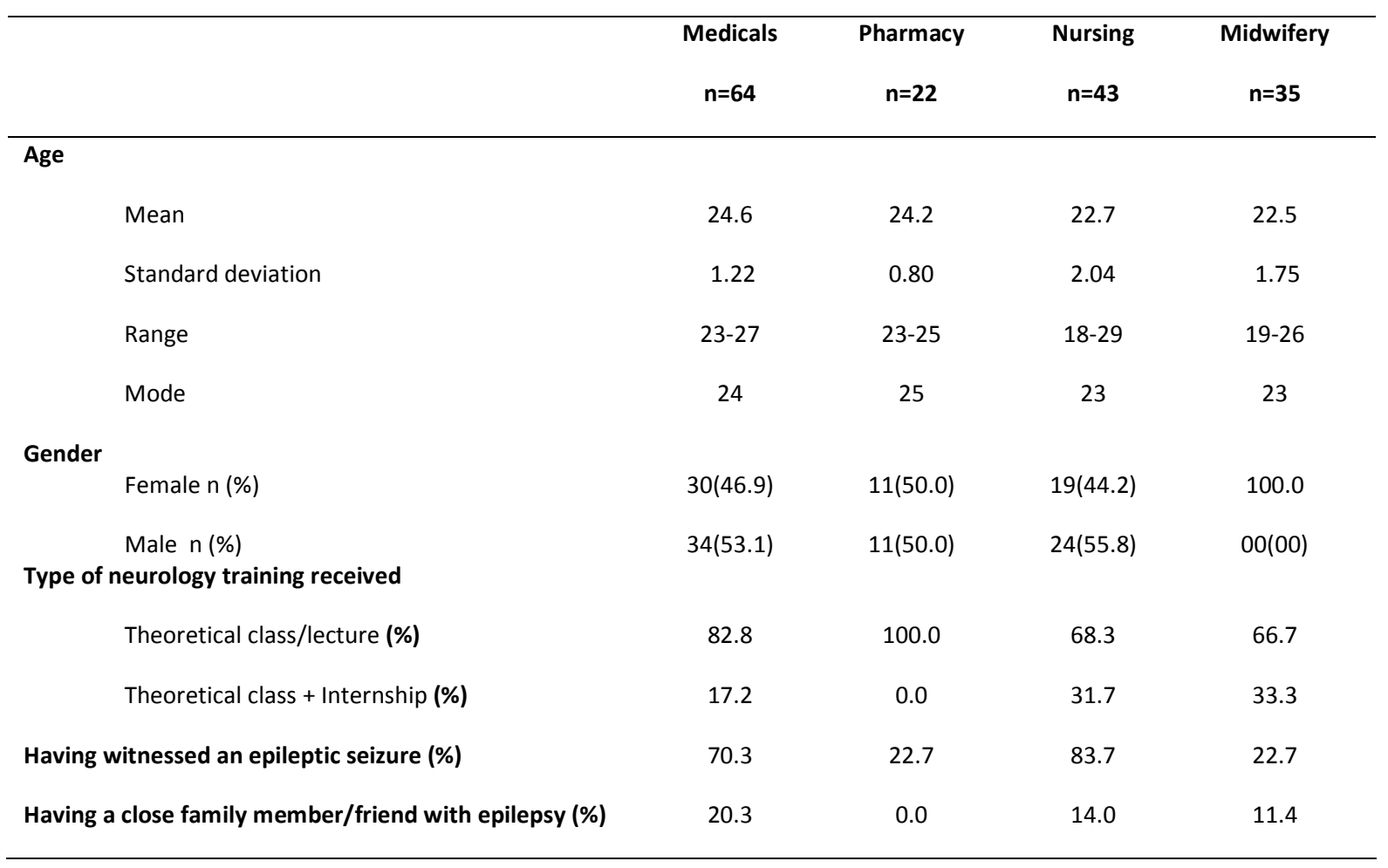




\section{Table 2: Knowledge of health sciences students about epilepsy}

\begin{tabular}{lccccc}
\hline & Medicals & Pharmacy & Nursing & Midwifery \\
& $n=64$ & $n=22$ & $n=43 \quad$ & $n=35 \quad$ n
\end{tabular}

At what age can epilepsy occur?

Any age \%

What can cause epilepsy?

Disorder of the central nervous system \%

A psychiatric disorder \%

All children born to parents with epilepsy will develop epilepsy

True \%

An individual who has sustained a head injury has a higher risk of developing epilepsy in the future

True \%

Epilepsy always manifests as seizures

True \%

All seizures equal epilepsy

False \%

Type of seizures/Signs may be found during an epileptic seizure

Generalized seizure (\%)

Partial seizure (\%)

Absence seizure (\%)

Hallucinations (\%)

Grinding of the teeth (\%)

Rolling of the eyes (\%)

Generalized loss of body tone (\%)

Knowledge score (mean, standard deviation)
96.9

72.7

93.0

77.1

100.0

100.0

93.0

100

6.3

0.0

20.9

22.9

11.9

42.9

45.5

69.8

20

34.4

81.8

60.5

82.9

100.0

86.4

100.0

100.0

100

72.1

62.9

65.6

0.0

32.6

14.3

56.3

18.2

44.2

11.4

10.9

0.0

2.3

11.4

64.1

0.0

44.2

25.7

70.3

18.2

51.2

48.6

56.3

40.9

41.9

28.6

8.7 (1.3)

$7.2(1.4)$

7.6 (1.3)

5.7 (1.5) 


\section{Table 3: Practices of health sciences students regarding person with epilepsy}

\begin{tabular}{lccccc}
\hline & Medicals & Pharmacy & Nursing & Midwifery \\
& $n=64$ & $n=22$ & $n=43$ & $n=35 \quad n$
\end{tabular}

What should you do when faced with a generalized

tonic-clonic seizure?

- Stop the seizure by overpowering the individual through force (\%)

4.7

to prevent the jaws from closing (\%)

- Protect the individual by moving them away from dangerous objects (\%)

- Administer anticonvulsants via the mouth (\%)

- Comfort the individual until the seizure is over (\%)

Epilepsy can be treated

True (\%)

An individual with epilepsy can be permanently cured of the disorder

True \%

Pharmaceutical antiepileptic treatment continues

throughout the individual's life

True \%

The individual can stop taking the antiepileptic drugs as soon as the seizures stop

True \%

Individuals with epilepsy must adhere to a certain number of dietary restrictions

$$
\text { True \% }
$$

Which of the following situations are not advisable

Teaching
Working at height
Driving

Practice Score (mean, standard deviation)

90.6 for individuals with uncontrolled epilepsy?

0.0

4.7

25.7

$$
\text { Working at height }
$$

88.4

$4.1(1.6) \quad 3.9(1.4) \quad 2.3(1.4)$


Table 4: Variables associated with the overall level of knowledge about epilepsy

\begin{tabular}{lccc}
\hline & Number (\%) & $\begin{array}{c}\text { Overall KAP } \\
\text { score }\end{array}$ & p value \\
\hline $\begin{array}{l}\text { Training school } \\
\text { Medical }\end{array}$ & $64(39.0)$ & 23.3 & $<0.001$ \\
$\quad$ Pharmacy & $22(13.4)$ & 21.1 & \\
$\quad$ Nursing & $43(26.2)$ & 21.0 & \\
$\quad$ Midwifery & $35(21.3)$ & 17.2 & 0.187 \\
Age $\quad$ & & \\
$\quad$ 20 & $04(2.4)$ & 18.5 & \\
$\quad 20-24$ & $114(69.5)$ & 21.1 & $<0.001$ \\
$\quad 25-29$ & $46(28)$ & 21.3 & \\
Gender & & & \\
$\quad$ Male & $69(42.1)$ & 22.3 & \\
$\quad$ Female & $95(57.9)$ & 20.2 & \\
Having heard about epilepsy & & & \\
$\quad$ Yes & $152(92.7)$ & 21.3 & \\
$\quad$ No & $12(7.3)$ & 19.0 & \\
Type of neurology training received & & & \\
$\quad$ Theoretical class & $111(79.9)$ & 21.7 & \\
$\quad$ Theoretical class+ Internship & $28(20.1)$ & 21.8 & \\
Having witnessed an epileptic seizure & & & \\
$\quad$ Yes & $111(67.7)$ & 21.1 & \\
$\quad$ No & $53(32.3)$ & 21.0 & \\
How a seizure had been witnessed? & & & \\
$\quad$ Live & $98(88.3)$ & 21.0 & \\
$\quad$ Waching in a movie & $13(11.7)$ & 22.8 & \\
Having a close family member/relative & & & \\
$\quad$ Yes & $23(14.0)$ & 22.6 & \\
$\quad$ No & $119(72.6)$ & 21.2 & \\
$\quad$ Don't know & $22(13.4)$ & 19.0 & \\
\hline
\end{tabular}

We confirm that we have read the Journal's position on issues involved in ethical publication and affirm that this report is consistent with those guidelines. 